\title{
Remote Sensing of Forest LAI from Multitemporal Optical Satellite Images over Mountain Area
}

\author{
Yuechan Shi ${ }^{1,2}$, Guijun Yang ${ }^{1, *}$, Haikuan Feng ${ }^{1}$, and Renli Wang ${ }^{2}$ \\ ${ }^{1}$ Beijing Research Center for Information Technology in Agriculture, \\ Beijing 100097, China \\ ${ }^{2}$ Geomatics College, Shandong University of Science and Technology, \\ Qiangdao 266510, China
}

\begin{abstract}
Leaf area index (LAI) is one of the most important structural parameters in terrestrial ecosystems. In this study, multitemporal Landsat TM images covering experiment station in the northwest mountain areas of Beijing were acquired and in-situ forest LAI was measured. By correlation analysis of three vegetation indexes (NDVI, EVI and TGDVI) and LAI, it is found that the correlation between LAI and NDVI in exponential form behaved a good relativity. This model was applied in mapping multitemporal forest LAI. Further, the sensitivity of the models between vegetation indices and LAI were tested for the broadleaf forest, coniferous and mixed forests, respectively. The results show that the accuracy was improved both in broadleaf and mixed forests compared with the advanced findings which didn't take care of different vegetation types, except for conifer stands with little accuracy decreasing. However, the accuracy of all models has reached a significant level.
\end{abstract}

Keywords: remote sensing, landsat TM, forest, LAI, seasonal variability.

\section{Introduction}

Leaf area index (LAI) is an important ecological parameter used for characterizing the interface between a vegetation canopy and the atmosphere. And it is also crucial for quantifying the energy and mass exchange of terrestrial ecosystems (Sellers et al., 1986; Running et al., 1989; Bonan et al., 1993; Turner et al., 1999). Chen and Black (1992) defined LAI was a half of the total leaf area per unit ground surface area.

All the methods of obtaining LAI values can be classified into two categories: direct or indirect way (Xiang, 2004; Zhang, 2010). The traditional direct way by destructive sampling and litter collection are time- and strain- consuming. Both the optical instruments and remote-sensing method are classified as the indirect way. The optical instruments (e.g. the LAI-2000, TRAC, and hemispherical photography) were used to measure LAI through the gap fraction method (Inge, 2004). But, this method is limited due to the extent of observation only representing small-scale area. On the contrary, the remote sensing method could acquire the images at a moment covering large area.

\footnotetext{
* Corresponding author.

D. Li and Y. Chen (Eds.): CCTA 2012, Part II, IFIP AICT 393, pp. 1-9, 2013.

(C) IFIP International Federation for Information Processing 2013
} 
Most of previous researches on estimating LAI from optical satellite data are based on two approaches: empirical models and physical models (Weiss, 1999; Liang, 2003; Xing, 2010; Yang, 2010). The empirical model involved the relationship between LAI and vegetation indices, while physical model uses the inversion of canopy reflectance models. Due to the quantitative methods usually faced the problem of ill-posed inversion because too many parameters should be providing before inverting the model. Therefore, many scientists preferred to use the empirical model. The empirical model method, as a simple and practical way, is widely used (Chen, 1999; Turner, 1999; Luo, 2005; Pauline, 2008).

In this study, forest LAI was measured using Hemispherical Photography (Cambridge, UK) at experiment station and multitemporal Landsat5 TM images are acquired simultaneously. All image data were geometrically and radiometrically corrected with the DEM data. Three typical vegetation indices (NDVI, EVI and TGDVI) were calculated and selected through the correlative analysis method. This model was applied in mapping multitemporal forest LAI.

\section{Study Areas}

\subsection{In-Situ LAI Measurements}

The study area (Figure 1) is located in the northwest mountain areas of Beijing, China $\left(116^{\circ} 0^{\prime} 38^{\prime \prime} \mathrm{E}-116^{\circ} 8^{\prime} 43^{\prime \prime} \mathrm{E}, 40^{\circ} 0^{\prime} 48^{\prime \prime} \mathrm{N}-40^{\circ} 4^{\prime} 59^{\prime \prime} \mathrm{N}\right)$ with an elevation of 150-1265 m. With the semi-humid continental monsoon climate in warm temperate zone, the woodland area is 823.04 hectares and the rate of forest coverage reached $96.2 \%$. Broadleaf and broadleaf-coniferous mixed forests, shrub and meadow extensively distribute in the study area in relatively homogenous spatial patterns.

Five ground-based forest LAI measurements were conducted using Hemispherical Photography over study areas from April to October, 2011.The histogram of LAI seasonal variability was given in Figure 2. Each plot was designed $30 \mathrm{~m} \times 30 \mathrm{~m}$, which is the same size with the pixel of Landsat5 TM data. The geographic coordinates of the centre place of plots were measured with GPS (Trimble Geo XT). The forest type

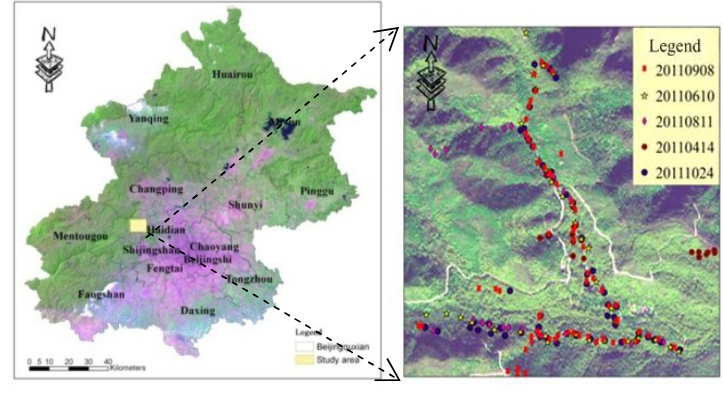

Fig. 1. The location of study areas and in-situ Measurements

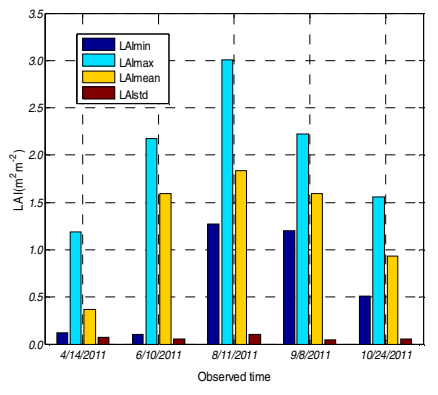

Fig. 2. The histogram of observed LAI with the seasonal variability 
was also recorded. Hemispherical photography is a technique for studying plant canopies via photographs acquired through a hemispherical (fisheye) lens with $180^{\circ}$ field of view from beneath the canopy (oriented towards zenith) or placed above the canopy looking downward.

\subsection{Multitemporal Landsat5 TM Data and DEM Data}

Multitemporal Landsat5 TM data were acquired coincident with the ground measurements. They are acquired respectively in April 15, 2009, June 5, 2010, August 8, 2010, September 22, 2009 and October 24, 2009. All image were geometrically corrected to a subpixel accuracy $(<10 \mathrm{~m})$ and GPS measurements. They were projected to UTM coordinates (WGS84 datum). Topographic and atmospheric calibration was performed combined with the DEM data.

The DEM data covering the study area with a resolution of $30 \mathrm{~m}$ were received from the NASA Land Processes Distributed Active Archive Center (LP DAAC), which were produced from optical stereo data of the Advanced Space borne Thermal Emission and Reflection Radiometer (ASTER). ASTER GDEM is in geotiff format with geographic lat/long coordinates (WGS84 datum). According to the zenith angle, azimuth angle and imaging time, the DEM data was used to calculate the slope, aspect, skyview and shadow factors which are the parameters of terrain radiometric correction.

\section{$3 \quad$ Analyze and Result}

\subsection{Inversion LAI Model}

Three vegetation indices (NDVI, EVI and TGDVI) (Table 2) were employed for correlative analysis to LAI (Chen, 2011; Zhu, 2010; Robert, 2003). Normalized Difference Vegetation Index (NDVI).Compared to NDVI, Enhanced Vegetation Index (EVI) adds blue band, which used to further correction for aerosol residue and the impact of soil background on vegetation index (Li, 2010). According to the vegetation and soil spectral characteristics, Tang et al (2003) advanced Three Gradient Difference Vegetation Index (TGDVI) and indicated this index has advantages in a high saturation point and eliminating background effects.

In our study, vegetation indices, which extracted from matched spectral reflectance image using the GPS points, are used for corrective analysis in two cases: individual observed period and the whole observations. The accuracy in Table 3 indicated that the vegetation indices were little sensitive to LAI especially in August and September. Nerveless, when all the LAI observations are used to established model, the significance was increasing largely and they reached significant level (Table 4). The LAI inversion model based on NDVI showed the most performance (Fig. 3), the equation as follows.

$$
\mathrm{LAI}=0.042 \mathrm{e}^{4.6 * \mathrm{NDVI}}\left(\mathrm{R}^{2}=0.487\right)
$$


In Figure 4, the retrieved results were compared with the available LAI measurements with $\mathrm{R}^{2}$ of 0.44 and RMSE of 0.38 . The significance of retrieved LAI models improved considerably using all the LAI, which can be explained by: (1) the error caused by the signal LAI value makes stronger influence on the trend of NDVI with LAI changes in individual observed period than that in all observations. This situation can be detected in September in Figure 5 that the sample located in small NDVI value but large LAI value. (2) In contrast with individual observed period, the total dataset located in 2D space of NDVI-LAI uniformly, showing the trend of NDVI with LAI changes clearly. For example, $80 \%$ of LAI values ranged from $1.3 \mathrm{~m}^{2} \mathrm{~m}^{-2}$ to $1.8 \mathrm{~m}^{2} \mathrm{~m}^{-2}$ while NDVI from 0.7 to 0.78 in June. $68 \%$ of LAI values distributed from $0.7 \mathrm{~m}^{2} \mathrm{~m}^{-2}$ to $1.1 \mathrm{~m}^{2} \mathrm{~m}^{-2}$ while NDVI from 0.64 and 0.7 in October. A similar situation also existed in other months. But, the multitemporal samples extend the dynamic range obviously which LAI values change from $0.12 \mathrm{~m}^{2} \mathrm{~m}^{-2}$ to $3.01 \mathrm{~m}^{2} \mathrm{~m}^{-2}$ and NDVI from 0.46 to 0.92 . Further, showing in Figure 5, the April values are relatively in low value areas of 2D space of NDVI-LAI while the June, August and September values are relatively in high value areas, resulting in the trend of NDVI with LAI changes.

Table 1. Three selected vegetation indices

Table 2. The accuracy of the relationship between all LAI values and vegetation

\begin{tabular}{|c|c|c|c|c|c|}
\hline $\begin{array}{l}\text { Vegetation } \\
\text { Index }\end{array}$ & VI formulate & index & & & \\
\hline $\begin{array}{l}\text { NDVI } \\
\text { ( } \quad \text { Normalized } \\
\text { Difference } \\
\text { Vegetation Index) } \\
\text { EVI }\end{array}$ & $\begin{array}{l}\mathrm{NDVI}=\frac{\mathrm{NIR}-\mathrm{R}}{\mathrm{NIR}+\mathrm{R}} \\
\mathrm{NIR}-\mathrm{R}\end{array}$ & $\begin{array}{l}\text { Vegetat } \\
\text { ion } \\
\text { Index }\end{array}$ & $\operatorname{Liner}\left(R^{2}\right)$ & $\begin{array}{l}\text { Exponent( } \\
\left.\mathrm{R}^{2}\right)\end{array}$ & $\operatorname{Logarithm}\left(\mathrm{R}^{2}\right)$ \\
\hline $\begin{array}{l}\text { (Enhanced } \\
\text { Vegetation Index) }\end{array}$ & $\mathrm{EVI}=2.5 \overline{\mathrm{NIR}+6 \mathrm{R}-7.5 \mathrm{~B}+1}$ & NDVI & $0.456 * *$ & $0.487 * *$ & $0.454 * *$ \\
\hline $\begin{array}{l}\text { TGDVI } \\
\text { ( Three Gradient } \\
\text { Difference } \\
\text { Vegetation Index ) }\end{array}$ & $\mathrm{TGDVI}=\frac{\mathrm{NIR}-\mathrm{R}}{\lambda_{\text {nir }}-\lambda_{\text {nir }}}-\frac{\mathrm{R}-\mathrm{G}}{\lambda_{\mathrm{r}}-\lambda_{\mathrm{g}}}$ & TGDVI & $0.164 * *$ & $0.102 * *$ & $0.177^{* *}$ \\
\hline
\end{tabular}

Table 3. The accuracy of the relationship between LAI and vegetation index in different observed time

\begin{tabular}{llllllllll}
\hline \multirow{2}{*}{$\begin{array}{l}\text { Observed } \\
\text { Time }\end{array}$} & \multicolumn{2}{c}{ NDVI } & \multicolumn{4}{c}{ TGDVI } & \multicolumn{4}{c}{ EVI } \\
\cline { 2 - 9 } & Lin. & Exp. & Log. & Lin. & Exp. & Log. & Lin. & Exp. & Log. \\
\hline 20110414 & 0.062 & 0.047 & 0.049 & 0.195 & 0.05 & 0.166 & $0.272^{*}$ & 0.133 & 0.223 \\
20110610 & 0.123 & $0.154^{*}$ & 0.128 & 0.143 & 0.143 & 0.140 & 0.141 & $0.154^{*}$ & $0.149^{*}$ \\
20110811 & 0.001 & 0.002 & 0.001 & 0.001 & 0.002 & 0.001 & 0.003 & 0.002 & 0.002 \\
20110908 & 0.038 & 0.031 & 0.030 & 0.002 & 0.001 & 0.001 & 0.002 & 0.001 & 0.002 \\
20111024 & 0.001 & 0.003 & 0.001 & 0.022 & 0.021 & 0.031 & 0.049 & 0.043 & 0.037 \\
\hline
\end{tabular}

Note: * a significant level in 0.05. Lin., Exp. and Log. indicate Liner, Exponent and Logarithm model. 


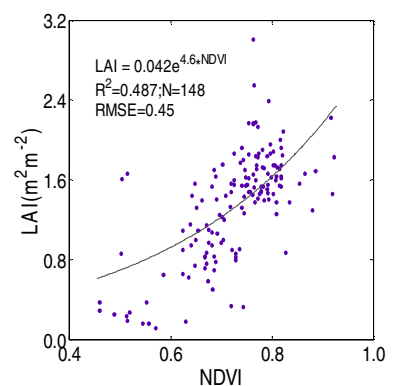

Fig. 3. Exponential model Between NDVI and LAI

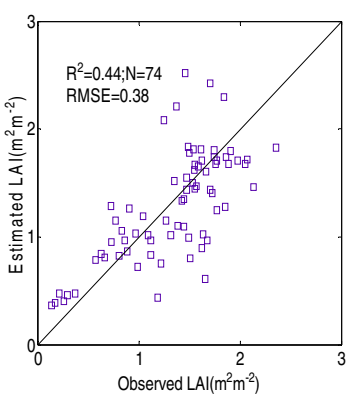

Fig. 4. Estimated and observed LAI

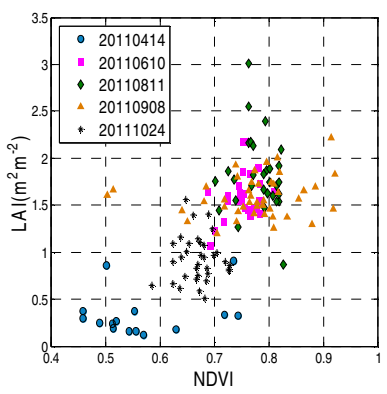

Fig. 5. The scatter of multitemporal LAI and NDVI

\subsection{Inversion of Forest LAI and Analysis of Seasonal Variability}

The retrieved forest LAI (Figure 6) show the seasonal variability from April to October. The estimated LAI value changes from $0-3.1 \mathrm{~m}^{2} \mathrm{~m}^{-2}$ and the April and October values(less than $1.5 \mathrm{~m}^{2} \mathrm{~m}^{-2}$ ) are lower than those in June, August and September $\left(0.5 \mathrm{~m}^{2} \mathrm{~m}^{-2}\right.$ to $\left.3.1 \mathrm{~m}^{2} \mathrm{~m}^{-2}\right)$. Both the dynamic range and seasonal variation of the retrieval LAI are consistent with the situation of ground-based LAI measurements (Figure 2). Those proved that LAI model based on multitemporal LAI values can be used for estimating individual seasonal map.

To further confirm applicability of this model, 180 samples are extracted from each estimated LAI map and used to explore the seasonal variability of estimated LAI values (Figure.7). We can see that LAI increased from April to August and decreased from August to October. The values reached the peak in August which is similar to the trend of ground-based LAI observations in Figure 2.

From figure 6, the most spatial distribution variation areas of forest LAI mainly located in Mentougou, Fangshan, Miyun, Huairou, Yanqing and Changping. In April, the value is obviously lower in Mentougou and Fangshan (less than $0.5 \mathrm{~m}^{2} \mathrm{~m}^{-2}$ ) than other regions (less than $1.5 \mathrm{~m}^{2} \mathrm{~m}^{-2}$ ). Through investigation, the difference is caused by the differences in vegetation type: Mentougou and Fangshan are mainly covered by bush while Huairou dominated covered by shelterbelts. With the growth of the vegetation, this difference becomes smaller especially in August.

In this part, the sensitivity of the models between vegetation indices and LAI were tested for the broadleaf forest, coniferous and mixed forests, respectively. Whatever the vegetation types is, the LAI value increased with NDVI and the values exceed in certain rang in LAI-NDVI 2D space (NDVI: 0.6-0.9; LAI: $0.5 \mathrm{~m}^{2} \mathrm{~m}^{-2}-2.5 \mathrm{~m}^{2} \mathrm{~m}^{-2}$ ) in Figure 8. We found that LAI model based on NDVI in exponential form is more sensitive than other models: broadleaf forest $\mathrm{R}^{2}=0.601$, coniferous $\mathrm{R}^{2}=0.432$ and mixed stands $\mathrm{R}^{2}=0.667$ (Table 5). Compared with aforementioned results which didn't take into account the effect of vegetation type, the significance of the relationship increased slightly both in broadleaf and mixed stands and decreased a little in conifer stand. However, the accuracy of all models has reached a significant level. 


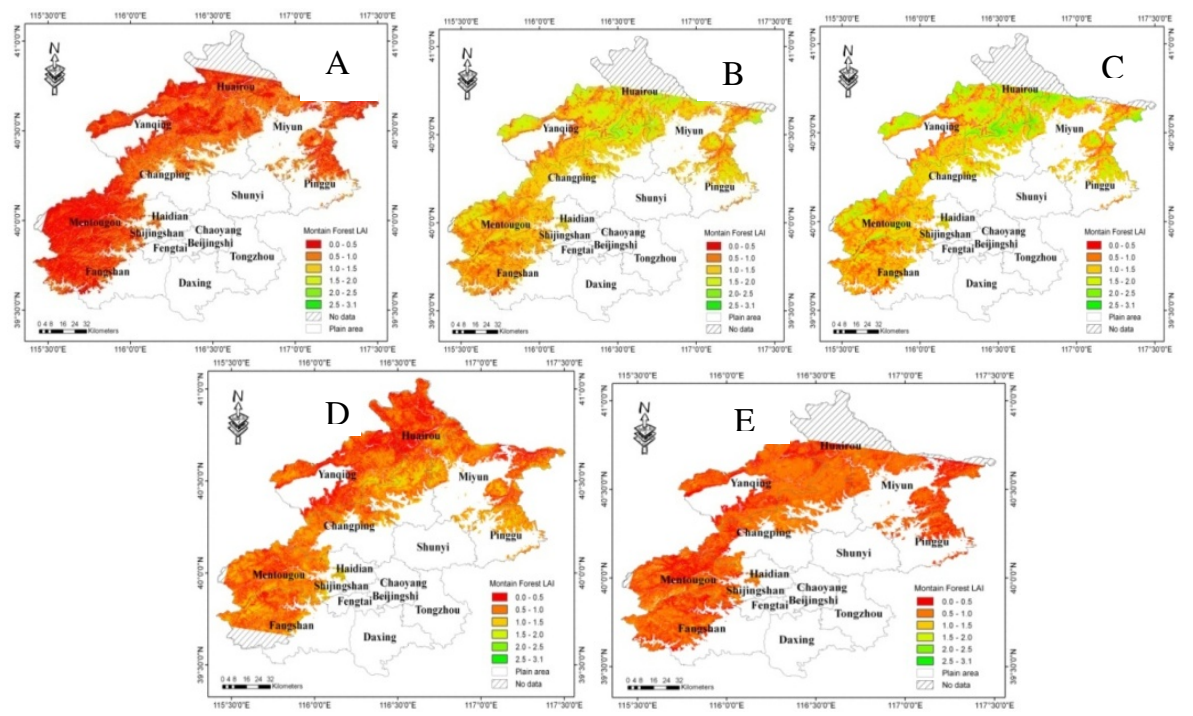

Fig. 6. Multitemporal Maps of retrieved forest LAI (A) Forest LAI map in April ; (B) Forest LAI map in June ; (C) Forest LAI map in August ; (D) Forest LAI map in September ; (E) Forest LAI map in October

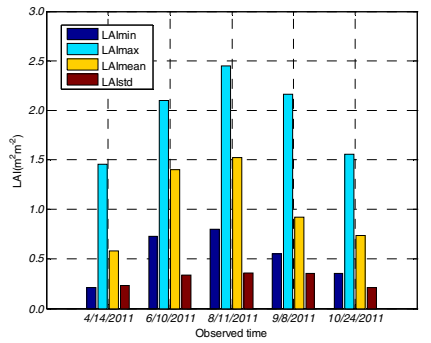

Fig. 7. The histogram of estimated LAI with the seasonal variability

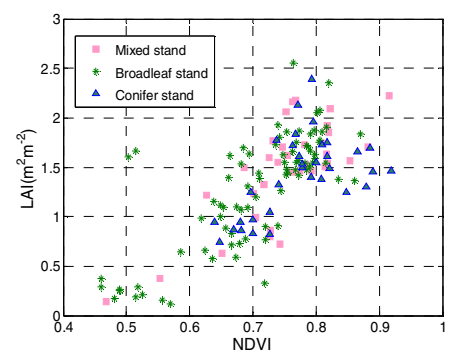

Fig. 8. The scatter of LAI and NDVI in different vegetation types

Table 4. The accuracy of the relationship between LAI and vegetation index in different vegetation types $\left(\mathrm{R}^{2}\right)$

\begin{tabular}{llllllllll}
\hline \multirow{2}{*}{$\begin{array}{l}\text { Vegetat- } \\
\text { ion index }\end{array}$} & \multicolumn{3}{c}{ Mixed forest } & \multicolumn{4}{c}{ Broadleaf forest } & \multicolumn{3}{c}{ Conifer forest } \\
\cline { 2 - 9 } & Lin. & Exp. & Log. & Lin. & Exp. & Log. & Lin. & Exp. & Log. \\
\hline NDVI & $0.578^{* *}$ & $0.667^{* *}$ & $0.585^{* *}$ & $0.579^{* *}$ & $0.601^{* *}$ & $0.566^{* *}$ & $0.402^{* *}$ & $0.432^{* *}$ & $0.418^{* *}$ \\
TGDVI & $0.143^{*}$ & $0.074^{*}$ & $0.136^{*}$ & $0.250^{* *}$ & $0.110^{* *}$ & $0.261^{* *}$ & $0.103^{*}$ & $0.112^{*}$ & $0.111^{*}$ \\
EVI & $0.122^{*}$ & $0.076^{*}$ & $0.106^{*}$ & $0.300^{* *}$ & $0.193^{* *}$ & $0.303^{* *}$ & $0.128^{*}$ & $0.141^{*}$ & $0.145^{*}$ \\
\hline
\end{tabular}

Note: * a significant level in $0.05 ; * *$ a significant level in 0.001 . 


\section{Conclusions}

The purpose of this paper is to retrieve forest LAI from multitemporal optical satellite images over mountain areas in Beijing. In-situ Forest LAI were measured using Hemispherical Photography. Three typical vegetation indices were employed, and the best index was selected through the correlative analysis method. The selected best LAI model is used to estimate forest LAI in this study. In the preprocessing of images, both terrain and atmospheric correction are conducted using DEM data. The major conclusions were drawn from this study as follows: the significance of the relationship between NDVI and LAI using all observations is better than others $\left(\mathrm{R}^{2}=0.487\right)$. The retrieved LAI maps presented seasonal variability, forest LAI increased from April to August and decreased from August to October, which was similar to the trend of observed LAI. These situations proved that LAI model based on multitemporal LAI measurement could more suitable be used in the inversion of individual seasonal LAI.

The sensitivity of the models between vegetation indices and LAI were tested for the broadleaf forest, coniferous and mixed forests, respectively. The results show that the accuracy was improved both in broadleaf and mixed forests if we take care of different vegetation types, except for conifer stands with little accuracy decreasing. However, the accuracy of all models has reached a significant level.

Acknowledgment. This work was supported in part by the State Key Basic Research and Development Program (2011CB311806), the National Natural Science Foundation of China (41071228, 41271345), the Beijing Municipal Natural Science Foundation (4102021), the Beijing Municipal Talents Training Funded Project (2012D002020000007), the Special Funds for Technology innovation capacity building sponsored by the Beijing Academy of Agriculture and Forestry Sciences (KJCX201104012), and the State Key Laboratory of Remote Sensing Science sponsored by the Institute of Remote Sensing Applications of Chinese Academy of Sciences, through its open funds (OFSLRSS201109).

\section{References}

1. Bonan, G.B.: Importance of leaf area index and forest type when estimating photosynthesis in boreal forests. Remote Sensing of Environment 43(3), 303-314 (1993)

2. Chen, J.M., Rich, P.M., Gower, S.T., Norman, J.M., Plummer, S.: Leaf area index of boreal forests: Theory, techniques and measurements. Geophys. Res. 102, 29429-29443 (1997)

3. Chen, C., Zhu, Y., Li, X.: The Applicability of Different Methods for Retrieving Leaf Area Index of Forests in Red Soil Hilly Regions. Acta Agriculturae Universitatis Jiangxiensis 33(3), 508-513 (2011)

4. Yang, G., Huang, W., Wang, J., Xing, Z.: Inversion of Forest Leaf Area Index Calculated from Multi-source and Multi-angle Remote Sensing Data. Chinese Bulletin of Botany 45(5), 566-578 (2010) 
5. Huete, A.R., Liu, H.Q., Batchily, K., Van Leeuwen, W.: A comparison of vegetation indices over a global set of TM images for EOS-MODIS. Remote sensing of Environment 59(3), 440-451 (1997)

6. Jonckheere, I., Fleck, S., Nackaerts, K., Muys, B., Coppin, P., Weiss, M., Bare, F.: Review of methods for in situ leaf area index determination Part I. Theories, sensors and hemispherical photography. Agricultural and Forest Meteorology 121, 19-35 (2004)

7. Chen, J.M., Leblanc, S.G., Miller, J.R., Freemantle, J., Loechel, S.E., Walthall, C.L., Innanen, K.A., Peter White, H.: Compact Airborne Spectrographic Imager (CASI) used for mapping biophysical parameters of boreal forests. Journal of Geophysical Research 104(22), 27945-27958 (1999)

8. Liang, S.L., Fang, H., Thorp, L., Kaul, M., Niel, T.G.V., McVicar, T.R.: Estimation and validation of land surface broadband albedos and leaf area index from EO-1 ALI data. IEEE Transactions on Geosciences and Remote Sensing 41(6), 1260-1267 (2003)

9. Li, W.-M., Qin, Z.-H., Li, W.-J., Yang, Q.: Comparison and Analysis of MODIS NDVI and MODIS EVI. Remote Sensing Information 6, 73-78 (2010)

10. Luo, Z.-M., Tian, Q.-J., Hui, F.-M.: Retrieving Leaf Area Indices for Coniferous Forest in Xingguo County, Jiangxi Province, in Use of Landsat ETM + Images. Journal of Nanjing University (Natural Sciences) 41(3), 253-258 (2005)

11. Mao, R.: Study on LAI Extraction Based on Landsat Image. Nanjing Normal University (2004)

12. Stenberg, P., Rautiainen, M., Manninen, T., Voipio, P., Mottus, M.: Boreal forest leaf areas index from optical satellite images: model simulations and empirical analyses using data from central Finland. Boreal Environment Research 13, 433-443 (2008)

13. Rouse, J.W., Haas, R.H., Schell, J.A., Deering, D.W.: Monitoring vegetation systems in the Great Plains with ERTS. In: Proceedings of the Third ERTS Symposium, vol. 1, pp. 48-62 (1973)

14. Rich, P.M., Clark, D.B., Clark, D.A., Oberbauer, S.F.: Long-term study of solar radiation regimes in a tropical wet forest using quantum sensors and hemispherical photography. Agric. For. Meteorol. 65, 107-127 (1993)

15. Colombo, R., Bellingeri, D., Fasolini, D., Marino, C.M.: Retrieval of leaf area index in different vegetation types using high resolution satellite data. Remote Sensing of Environment 86(1), 120-131 (2003)

16. Running, S.W., Nemani, R.R., Peterson, D.L., Band, L.E., Potts, D.F., Pierce, L.L., Spanner, M.A.: Mapping regional forest evapotranspiration and photosynthesis by coupling satellite data with ecosystem simulation. Ecology 70(4), 1090-1101 (1989)

17. Sellers, P.J., Mintz, Y., Sud, Y.C., et al.: A simple biosphere model (SiB) for use within general circulation models. Journal of the Atmospheric Sciences 43, 505-531 (1986)

18. Turner, D.P., Cohen, W.B., Kennedy, R.E., Fassnacht, K.S., Briggs, J.M.: Relationships between leaf area index, FPAR, and net primary production of terrestrial ecosystems. Remote Sensing of Environment 70, 52-68 (1999)

19. Turner, D.P., Cohen, W.B., Kennedy, R.E., Fassnacht, K.S., Briggs, J.M.: Relationship between leaf area index and Landsat TM Spectral Vegetation Indices across three temperate zone sites. Remote Sens. Environ. 70, 52-68 (1999)

20. Tang, S.-H., Zhu, Q.-J.: Theoretical basis and application of Three Gradient Difference Vegetation Index. Science China (Series D) 11(33), 1094-1102 (2003)

21. Weiss, M., Baret, F.: Evaluation of canopy biophysical variable retrieval performances from the accumulation of large swath satellite data. Remote Sens. Environ. 70(3), 293-306 (1999) 
22. Xiang, H., Guo, Z., Zhao, Z., Wang, J.: Estimating Method of Forest Leaf Areas Index on Different Space Scales. Scientia Silvae Sinicae 45(6), 139-144 (2004)

23. Xing, Z., Feng, Y., Li, W., Wang, P., Yang, G.: The research status of inversion of leaf area index with hyperspectra 1 remote sensing. Science of Surveying and Mapping 35(S1), 162-164 (2010)

24. Zhang, J., Zhang, G., Wang, P.: Vegetation and Ecological Remote Sensing. Science Press, Beijing (2010)

25. Zhao, Y.: Principles and Analysis of Remote Sensing Application. Science Press, Beijing (2003)

26. Zhu, G.-L., Ju, W.-M., Chen, J.M., Fan, W., Zhou, Y., Li, X., Li, M.: Forest canopy leaf area index in Maoershan Mountain: Ground measurement and remote sensing. Chinese Journal of Applied Ecology 21(8), 2117-2124 (2010) 